\title{
Measuring Stigma and Discrimination towards People Living with HIV among Health Care Workers in a Tertiary, Government Teaching Hospital in the Philippines
}

\author{
Sheryl Mae J. Lopez, ${ }^{1}$ Valerie R. Ramiro ${ }^{1}$ and Evalyn A. Roxas ${ }^{2,3}$ \\ ${ }^{1}$ Department of Medicine, Philippine General Hospital, University of the Philippines Manila \\ ${ }^{2}$ Section of Infectious Diseases, Department of Medicine, College of Medicine and Philippine General Hospital, University of the Philippines Manila \\ ${ }^{3}$ Department of Medical Microbiology, College of Public Health, University of the Philippines Manila
}

\begin{abstract}
Background. The incidence of human immunodeficiency virus (HIV) infection in the Philippines is increasing. HIV-related stigma in the health care setting is a known barrier to healthcare access for people living with HIV (PLHIV).
\end{abstract}

Objective. The study aimed to identify stigmatizing attitudes and practices towards PLHIV among healthcare workers in Philippine General Hospital.

Methods. In this cross-sectional descriptive study, 375 healthcare workers were recruited via convenience sampling. A standardized questionnaire developed by the Health Policy Project was used.

Results. The study demonstrated concerns regarding transmission, particularly during drawing blood (87.1\%), assisting in labor and delivery (82\%), and dressing wounds (80.4\%). Use of special infection-control measures $(76.1 \%)$, wearing double gloves (72.8\%), additional infection-control procedures during labor and delivery (72.2\%), and wearing gloves during all aspects of patient care (70.2\%) were reported as well. Perceptions such as the belief that pregnant women who are HIV positive must inform their families of their HIV status $(82.1 \%)$, and that PLHIV engage in irresponsible behaviors (69.1\%) and are promiscuous (66.4\%) were also detected.

Conclusion. The study confirmed the presence of HIV-related stigma among healthcare workers in Philippine General Hospital. This finding could potentially catalyze the development of stigma-reducing measures which could hopefully translate to improved healthcare for PLHIV.

Key Words: discrimination, health care setting, health care workers, HIV, stigma

Corresponding author: Sheryl Mae J. Lopez, MD

Department of Medicine

Philippine General Hospital

University of the Philippines Manila

Taft Ave. Ermita, Manila, 1000 Philippines

Telephone: +63209335888146

Email: lopez.sherylmaej@gmail.com

\section{Introduction}

Human Immunodeficiency Virus (HIV) infection and Acquired Immune Deficiency Syndrome (AIDS) remain a global epidemic. In 2014, 36.9 million people worldwide were living with HIV. ${ }^{1}$ In the Philippines, the national prevalence of $\mathrm{HIV}$ among adults is reported at $<0.1 \%{ }^{2}$ However, the number of cases is increasing; the UNAIDS Global Report in 2010 identified the Philippines as one of only seven countries with a $25 \%$ increase of new HIV cases from 2001 to $2009 .^{3}$

Stigma is described by the Joint United Nations Programme on HIV/AIDS (UNAIDS) as a "dynamic process of devaluation that significantly discredits an individual in the eyes of others...When stigma is acted upon, the result is discrimination that may take the form of actions or omissions". UNAIDS further describes discrimination as "any form of arbitrary distinction, exclusion, or restriction affecting a person, usually but not only by an inherent personal characteristic or perceived belonging to a specific group - in the case of AIDS, a person's confirmed or suspected HIV-positive status - irrespective of whether or not there is any justification for these measures." 4

Numerous studies have shown that stigma and discrimination towards PLHIV have significant impact on their health. A meta-analysis by Logie et al concluded that stigma experienced by PLHIV was associated with poor physical and mental health. ${ }^{5}$ In a study done in Iran, reactions of PLHIV to perceived stigma and discrimination from health care workers include poor health seeking behavior (eg, avoiding or delaying seeking care and not disclosing their HIV status) and emotional responses (eg, feeling undeserving of care, a decreased motivation to stay healthy, and emotional stress). ${ }^{6}$ Stigma as reported by PLHIV in the health care setting of various countries include refusal of care, ${ }^{3,6,7}$ suboptimal care ${ }^{6,7}$ excessive precautions, ${ }^{6}$ physical distancing, ${ }^{6}$ confidentiality breach, ${ }^{7}$ and humiliation and blaming. ${ }^{6}$

From the health care workers' perspective, reported stigmatizing attitudes and discriminatory practices include breach of confidentiality (ie, disclosing the patient's HIV status to the family and to staff not directly involved in treating for the patient), $, 7,8,9,10$ unnecessary infection control 
measures (ie, burning linen used by PLHIV, using gloves only in HIV patients, avoiding going near the patient), $7,8,10$ testing a patient suspected to have HIV without consent and counselling, ${ }^{8}$ and attitudes of blame and judgment. ${ }^{9}$ In a study conducted in Nigeria, less than $10 \%$ of health care workers admitted to refusing care and/or hospital admission for PLHIV, while majority of their respondents reported witnessing other health professionals refuse care (67\%) and admission (43\%) for PLHIV. ${ }^{11}$ In India, a survey of health care workers showed majority (63\%) incorrectly classifying the risk of occupational infection as high, with $78 \%$ agreeing to the isolation of all PLHIV from other patients and 95\% to mandatory HIV testing of obstetric and surgical patients. ${ }^{12}$

As future health care professionals, health care students were also recruited in several studies investigating HIV-related stigma. Philip et al surveyed health care students in Trinidad and Tobago, and concluded that stigmatizing attitudes of respondents are dependent on the mode of acquiring HIV, with departure to social norms (ie, promiscuity) correlating to greater stigma. ${ }^{13}$ Jin et al surveyed health care students in Malaysia using an attitude scale and obtained lower scores for PLHIV and males having sex with males compared to the general population. ${ }^{14}$ Platten et al surveyed medical students and correlated awareness of stigma and discrimination with nonprejudicial, nondiscriminatory attitude to HIV/AIDS at the workplace. ${ }^{15}$

Several tools have been developed and validated to measure HIV-related stigma among health care workers. However, most have not been used across diverse contexts or in multiple countries.10,16,17 For this reason, the Health Policy Project (HPP), in partnership with the US Agency for International Development (USAID) developed a standardized questionnaire aimed to facilitate data collection across diverse settings from health care facility staff (both clinical and non-clinical), detect and monitor stigma, and thereby assist in the development of stigma-reduction programs in these facilities. The questionnaire intended to capture main drivers of stigma (fear of HIV transmission, stereotypes and prejudice, and health facility policies) and its discriminatory manifestation in the health care setting. The questionnaire was field tested in 1,893 health care workers in 6 countries worldwide (China, Dominica, Egypt, Kenya, Puerto Rico, St. Christopher \& Nevis). ${ }^{18}$ It has been made publicly available by the developers free of charge.

In the Philippine context, a study conducted in 2009 to 2010 revealed that among the 80 PLHIV respondents, $61.3 \%$ disclosed their HIV status to health care workers. Because of their HIV status, $12.5 \%$ reported being denied health services including dental care, with $6.3 \%$ denied family planning services and $3.8 \%$ denied sexual and reproductive health services. ${ }^{19}$ Efforts by the Philippine government to increase HIV awareness have been in place since the 1990s, with the Philippine AIDS Prevention and Control Act in 1998 and the creation of the Philippine National AIDS Council under the Department of Health in 1992. Nongovernment and international organizations such as UNAIDS and the AIDS Society of the Philippines also contribute to programs that prevent and control the spread of HIV/AIDS. ${ }^{20}$

\section{General objective}

To identify the stigmatizing attitudes and discriminatory practices among health care workers in a tertiary, teaching hospital in the Philippines towards people living with HIV/AIDS.

\section{Specific objectives}

1. To describe the demographics and baseline characteristics of health care workers (doctors, nurses, dentists, phlebotomists, medical students) in Philippine General Hospital.

2. To enumerate stigmatizing attitudes and discriminatory practices of health care workers in Philippine General Hospital (PGH) towards people living with HIV/AIDS.

3. To measure stigma and discrimination of health care workers towards people living with HIV/AIDS with regard to the following areas:
a. Infection concerns in the facility
b. Health facility environment and practices
c. Health facility policies
d. Opinions on PLHIV
e. Antenatal care, prevention of mother to child transmission, labor and delivery wards

\section{Methods}

\section{Study Design}

This is a cross sectional, descriptive study. It was conducted at the Philippine General Hospital (PGH), a tertiary, teaching hospital in the Philippines.

\section{Participants}

Doctors, nurses, medical students, dentists, and phlebotomists assigned in the Medicine, Surgery, Obstetrics and Gynecology, Neurology, Dermatology, Anesthesiology, Otolaryngology, Ophthalmology, and Orthopedics charity wards, emergency room, operating rooms, pay floors and outpatient department on August-September 2016 were included in the study. Individuals who did not consent or agree to sign the informed consent form provided; or individuals who are not able to read and/or understand written English were not included in the study.

\section{Overview of methods}

The study was conducted after review and approval of the hospital ethics review board. 
Participants were recruited through convenience sampling. Point persons were oriented regarding the study objectives and methodology by the investigators, and they were advised that participation in the study is voluntary and unnamed. Informed consent forms were provided for those who agreed to be part of the study.

Once a participant signed the informed consent form, he/she was asked to fill out a brief, 25-item, English, selfadministered questionnaire. The completed questionnaires were then collected in unmarked sealed envelopes by the investigators personally. These were kept in a secured location for a period of 1 year after completion of the study then discarded by shredding.

The following data were obtained and recorded based on the participant's answers on the questionnaire: background information and demographics, infection concerns within the facility, observed practices and policies in the facility, and opinions about people living with HIV/AIDS. Responses to questions regarding attitudes and practices to patients with HIV were likewise recorded.

\section{Data analysis and sample size computation}

We collected both continuous and categorical data. Socio-demographic data and responses that are associated with stigmatizing attitudes and discriminatory behavior were then recorded, with average frequencies reported.

Based on the results of the UNAIDS Study conducted by Nyblade et al in 2013, stigmatizing behavior among health care workers was present in around 20 to $30 \%{ }^{18}$. Using this observed prevalence and accepting a 95\% confidence interval for precision, our computed sample size was 341 participants.

\section{Results}

\section{Baseline characteristics}

Among the 521 questionnaires distributed, 375 were answered and submitted to the investigators, yielding a response rate of $72 \%$. The mean reported age of the participants was 29.7 years, with values ranging from 20 to 62 years. Majority of the participants were medical doctors $(37.3 \%)$ and nurses (38.1\%). Among the respondents, $77.6 \%$ correctly identified the PGH setting as a low prevalence area, and reported the estimated number of patients per year, with a mean of 4.1 patients/year. Some (27.2\%) respondents incorrectly perceived the setting as a high prevalence area. Most respondents reported having some training on infection control and universal precautions $(78.9 \%)$, and on informed consent, privacy and confidentiality (62.4\%). A lower percentage reported having training on stigma and discrimination in HIV and key populations (i.e. people who use drugs, men who have sex with men, and sex workers). Table 1 lists the baseline characteristics of the participants.
Table 1. Demographic data $(\mathbf{n}=\mathbf{3 7 5})$

\begin{tabular}{|c|c|}
\hline Baseline characteristics & $\begin{array}{l}\text { Percentage / } \\
\text { Mean Value }\end{array}$ \\
\hline Age, mean (in years) $(\mathrm{n}=368)$ & 29.7 \\
\hline \multicolumn{2}{|l|}{$\operatorname{Sex}(\%)(n=374)$} \\
\hline Male & 36.9 \\
\hline Female & 63.1 \\
\hline \multicolumn{2}{|l|}{ Occupation (\%) (n=375) } \\
\hline Medical Doctor & 37.3 \\
\hline Dentist & 5.6 \\
\hline Medical technician/phlebotomist & 2.4 \\
\hline Medical Student & 16.5 \\
\hline Nurse & 38.1 \\
\hline Years in healthcare, mean $(n=367)$ & 6.1 \\
\hline $\begin{array}{l}\text { Worked in hospital/clinic/department } \\
\text { specializing in HIV }(\%)(n=370)\end{array}$ & 37.3 \\
\hline $\begin{array}{l}\text { Number of HIV patients provided with care/services } \\
(\mathrm{n}=291) \\
\text { (Low prevalence: in the past } 12 \text { months) } \\
\text { Training in (\%): }\end{array}$ & 4.1 \\
\hline - HIV stigma and discrimination $(\mathrm{n}=375)$ & 28.5 \\
\hline $\begin{array}{l}\text { - Infection control and universal precautions (including } \\
\text { post-exposure prophylaxis) }(\mathrm{n}=375)\end{array}$ & 78.9 \\
\hline $\begin{array}{l}\text { - Patients' informed consent, privacy, and confidentiality } \\
(\mathrm{n}=375)\end{array}$ & 62.4 \\
\hline - Key population stigma and discrimination (n=375) & 21.3 \\
\hline
\end{tabular}

The top stigmatizing behaviors and discriminatory practices identified are listed in Table 2. These are grouped into the following areas: concerns regarding HIV transmission, using extra infection measures when handling PLHIV, and attitudes and opinions towards PLHIV.

Some of the respondents preferred not to provide services to key populations. There were $26.3 \%$ of respondents who preferred not to provide services to people who inject illegal drugs, $7.8 \%$ who preferred not to provide services to men who have sex with men, and $13.2 \%$ who preferred not to provide services to sex workers (Appendix, Table D).

\section{Concerns regarding HIV transmission}

Majority of the respondents expressed concern regarding HIV transmission through drawing blood $(87.1 \%)$ and dressing the wounds of PLHIV (80.4\%), as well as assisting in the delivery of a woman living with HIV (82\%) (Table 2).

Similarly, most of the respondents who preferred not to provide services to key populations cited concerns regarding HIV transmission as one of the reasons why they preferred not to provide such services. For instance, among those who preferred not to provide services to persons who inject illegal drugs, $84.9 \%$ believed that doing so would put them at high risk for disease. This was also one of the reasons cited by most respondents who preferred not to provide services to men who have sex with men (85.2\%) and sex workers (83.3\%) (Appendix, Table D). 
Table 2. Top HIV-related stigmatizing attitudes and discriminatory practices among health care workers.

\begin{tabular}{|c|c|}
\hline Concerns regarding HIV transmission & Percentage \\
\hline Worried about drawing blood from a PLHIV $(n=371)$ & $87.1 \%$ \\
\hline Worried about assisting in labor and delivery if the woman is living with HIV ( $\mathrm{n}=283$ ) & $82.0 \%$ \\
\hline Worried about dressing the wounds of a PLHIV $(\mathrm{n}=372)$ & $80.4 \%$ \\
\hline \multicolumn{2}{|l|}{ Using extra infection measures when handling PLHIV } \\
\hline Typically use any special infection-control measures with PLHIV that are not usually used with other patients $(n=368)$ & $76.1 \%$ \\
\hline Typically wear double gloves $(\mathrm{n}=371)$ & $72.8 \%$ \\
\hline $\begin{array}{l}\text { Observe additional infection-control procedures (eg, double gloves) typically used with a pregnant woman living with HIV during labor and } \\
\text { delivery }(\mathrm{n}=263)\end{array}$ & $72.2 \%$ \\
\hline Typically wear gloves during all aspects of patient care $(n=369)$ & $70.2 \%$ \\
\hline \multicolumn{2}{|l|}{ Attitudes and opinions towards PLHIV } \\
\hline Agree that if a pregnant woman is HIV positive, her family has a right to know $(\mathrm{n}=274)$ & $82.1 \%$ \\
\hline Agree that people get infected with HIV because they engage in irresponsible behaviors ( $\mathrm{n}=369)$ & $69.1 \%$ \\
\hline Agree that most people living with HIV have had many sexual partners $(n=369)$ & $66.4 \%$ \\
\hline
\end{tabular}

$\mathrm{n}=$ number of responses*

*Some respondents left some questions with blanks or no answers; these were not included in the number of responses for the particular question.

\section{Using extra infection measures when handling PLHIV}

The study revealed the practice of extra infection measures by majority of the respondents. The most common practices were the use of any special infection control measures not used with other patients $(76.1 \%)$, wearing double gloves $(72.8 \%)$, and the wearing of gloves during all aspects of patient care $(70.2 \%)$. Furthermore, $72.2 \%$ of respondents observed the use of additional infection control procedures during labor and delivery of a woman living with HIV (Table 2).

\section{Attitudes and opinions towards PLHIV}

Many respondents believed that most PLHIV had multiple sexual partners $(66.4 \%)$ and engaged in irresponsible behaviors (69.1\%) (Table 2). A similar belief was found among those who preferred not to provide services to key populations. Among respondents who preferred not to provide services to persons with a history of injecting illegal drugs, $67.1 \%$ believed that this group engaged in immoral behavior. This reason was also cited by $70.8 \%$ of respondents who preferred not to provide services to men who have sex with men (Appendix, Table D). There were $82.1 \%$ of respondents who agreed that the family of a woman living with HIV has a right to know her status (Table 2).

\section{Discussion}

In the Philippine health care setting, PLHIV have had experiences being denied appropriate health care services because of their HIV status, as reported in the 2009 Stigma Index study. ${ }^{21}$ This may be in the form of denial of administration of HIV treatment, delivery of substandard care, breach in patient confidentiality, or even refusal of hospital admission for PLHIV. The reasons for PLHIV not receiving the needed health care are multifactorial and inevitably linked to stigma and discrimination towards this population. ${ }^{22}$

Our study has identified stigmatizing behaviors and discriminatory practices at the Philippine General Hospital.
The percentage of the respondents expressing concerns regarding HIV transmission in this study was greater than that reported in the study done by Nyblade, which had a sample size of 1,893 health care workers from 6 countries (China, Dominica, Egypt, Kenya, Puerto Rico, St. Christopher \& Nevis), ${ }^{18}$ both in dressing wounds $(80.4 \%$ vs $59.6 \%$ ) and drawing blood (87.1\% vs $67 \%$ ). Furthermore, among respondents who preferred not to provide services to key populations, majority believed that doing so would increase the risk for HIV transmission. The typical use of extra precautionary measures, both practiced and observed by majority of the respondents, may be linked to these concerns as well. Notably, a higher percentage of respondents in our study adhered to these practices compared to results in the study by Nyblade (eg, double gloving: $72.8 \%$ vs $30.9 \%$; use of any special measures when handling PLHIV not used with other patients: $76.1 \%$ vs $26.9 \%) .{ }^{18}$

Opinions on PLHIV also reflected stigmatizing behavior. Majority of the respondents in our study associated PLHIV with having many sexual partners (66.4\%) and irresponsible behaviors (69.1\%), both greater than that reported in the study by Nyblade $(35.8 \%$ and $38.1 \%$, respectively). ${ }^{18}$ Most also believed that the family of a pregnant woman living with HIV has the right to know her HIV status. Furthermore, most of the respondents who preferred not to provide services to key populations believed that these groups engaged in immoral behavior.

\section{Addressing stigma and discrimination towards PLHIV}

In a review done in 2009, three key causes of HIVrelated stigma were identified: lack of awareness, incomplete knowledge about HIV transmission, and values linking people with HIV to improper or immoral behavior. Programs to focus on the individual, environmental, and policy levels to address these causes were suggested. ${ }^{22}$

At the individual level, health care workers must be made aware of what stigma is and its negative consequences for PLHIV. Health care workers should have complete 
information about HIV transmission, as well as the effectiveness of universal precautions in preventing transmission.22 Workshops can be used to enable the participants to better understand PLHIV and consequently minimize the negative opinions associating immoral or irresponsible behaviors toward this population.

It is noteworthy that in our study, there is a perceived lack of training of health care workers on caring for persons living with HIV, and was reported to be especially low in the areas of HIV stigma and discrimination and key population stigma and discrimination. Training on infection control and universal precautions, while relatively higher, can still be improved as well. This may indicate a sense of awareness by the respondents of the need for such programs by the health care personnel which is a significant step forward to the goal of eliminating stigma and discrimination in our setting.

In the Philippines, national implementing rules and regulations of the Philippine AIDS Prevention and Control Act of 1998 (Republic Act 8504) already integrated the need for such programs, citing that: "HIV/AIDS education shall be integrated in the orientation, training, continuing education, and other human resource development programs of employees and employers in all government and private offices. Each employer shall develop, implement, evaluate, and fund a workplace HIV/AIDS education and information program for all their workers." While it states that employers have accountability, healthcare workers should likewise be involved and trained in the implementation of these programs for these measures to be truly successful. The Philippine National AIDS Council (PNAC) is tasked to ensure that all public health workers are trained on HIV/AIDS. ${ }^{23}$

Translating a national policy into a locally implemented program, however, is not always immediately feasible especially in a resource-limited setting such as ours. In this institution, the Hospital Infection Control Unit (HICU) is in charge of the implementation of such a program. Healthcare workers are highly encouraged to comply with universal precautions and use of personal protective equipment (PPEs) when handling patients with, or suspected to have, HIV. There are visible efforts by the hospital especially the clinical departments to ensure compliance by the staff members to the principles of standard and universal precautions (eg, gloving, appropriate handwashing, donning masks, proper disposal of sharps) to reduce transmission of infections in general, and not just HIV. Also, once HIV transmission is suspected (eg, exposure to bodily fluids, needlestick injuries), the HICU provides HIV screening and post-exposure prophylaxis at no cost to the healthcare worker.

Upon consultation with the HICU, there is no formal program currently in place with the purpose of increasing awareness of healthcare workers on HIV stigma. However, whenever interviews or consults at the HICU are made by any healthcare staff, they are informally advised on how to address or handle PLHIV. Given the observed high prevalence of stigma in our country and in this hospital, there is definitely a need to institute a structured, doable, and sustainable scheme to help our staff assess if they do have stigmatizing behaviors and attitudes and then take steps towards eliminating these so as to provide benevolent and equitable healthcare services to all patients regardless of HIV status. Once established, such a scheme or program could also look into compliance of healthcare staff on these policies and other benchmarks to evaluate the impact of stigma reduction on healthcare delivery to patients with HIV as well as satisfaction of healthcare workers in the workplace. This is particularly important since literature has shown that PLHIV consider perceived or actual discrimination from healthcare workers as deterrents to seeking timely consultation and treatment, despite antiretroviral treatment being given free of cost by the national government.

\section{Study limitations}

The questionnaire used was not validated in our setting. Some of the questions can be subject to different interpretations by the participants. For instance, some of the medical students and doctors may include their years of training in answering the number of years in healthcare, while others would only include their years of practice as licensed physicians. Another example would be the item regarding experience with a hospital/clinic/department specializing in HIV, where only $37.3 \%$ reported having such experience. Since the Philippine General Hospital specializes in HIV care, this statistic may be inaccurate due either to the participant's lack of knowledge or a misinterpretation of the question (ie, interpreting it as past rather than present experience or considering their section/department as not specialized in HIV care in particular). Similarly, the item regarding being in a low or high prevalence area had different responses despite the respondents all coming from the same hospital setting. The reason for this may be that some of the respondents was not aware of the Philippines being a low HIV prevalence area, or otherwise misinterpreted the question. Lastly, some respondents who answered that they were willing to provide care to key populations still answered items regarding reasons for not providing care for these populations, perhaps due to a misunderstanding of the instructions.

\section{Conclusion}

Our study demonstrated the presence of HIV-related stigma at the Philippine General Hospital, a government tertiary-level teaching hospital which offers health care and services to inpatient and outpatient HIV/AIDS patients. We are able to identify and describe the following stigmatizing attitudes and discriminatory practices and specific areas 
driving these behaviors that could be addressed: concerns regarding HIV transmission, use of extra infection measures in handling PLHIV, and opinions about people living with HIV/AIDS. The results of our study can potentially catalyze the development and implementation of programs addressing the individual, environmental, and policy levels to reduce HIV-related stigma of healthcare workers towards PLHIV and have a lasting impact on their healthcare.

\section{Statement of Authorship}

All authors have approved the final version submitted.

\section{Author Disclosure}

All authors declared no conflict of interest.

\section{Funding Source}

This paper was partially funded by the Philippine General Hospital and the authors.

\section{References}

1. Joint United Nations Programme on HIV/AIDS (UNAIDS). Factsheets 2015 [Online]. 2015 [cited 2016 Nov]. Available from http://unaids.org/.

2. Joint United Nations Programme on HIV/AIDS (UNAIDS). Country factsheets: Philippines [Online]. 2014 [cited 2016 Nov]. Available from http://aidsinfo.unaids.org/.

3. Joint United Nations Programme on HIV/AIDS (UNAIDS). Global report on the AIDS epidemic. Geneva: UNAIDS [Online]. 2010 [cited 2016 Nov]. Available from http://unaids.org/.

4. Joint United Nations Programme on HIV/AIDS (UNAIDS). UNAIDS Terminology Guidelines [Online]. 2011 [cited 2016 Nov]. Available from http://unaids.org/.

5. Logie C, Gadalla TM. Meta-analysis of health and demographic correlates of stigma towards people living with HIV. AIDS Care. 2009; 21(6):742-53.

6. Rahmati-Najarkolaei F, Niknami S, Aminshokravi F, et al. Experiences of stigma in healthcare settings among adults living with HIV in the Islamic Republic of Iran. J Int AIDS Soc. 2010; 13:27.

7. Stutterheim SE, Sicking L, Brands R, et al. Patient and provider perspectives on HIV and HIV-related stigma in Dutch health care settings. AIDS Patient Care STDS. 2014; 28(12):652-65.

8. Mahendra VS, Gilborn L, Bharat S, et al. Understanding and measuring AIDS-related stigma in health care settings: A developing country perspective. SAHARA J. 2007; 4(2):616-25.
9. Andrewin A, Chien LY. Stigmatization of patients with HIV/AIDS among doctors and nurses in Belize. AIDS Patient Care STDS. 2008; 22(11):897-906.

10. Feyissa G, Abebe L, Girma E, Woldie M. Validation of an HIV-related stigma scale among health care providers in a resource-poor Ethiopian setting. J Multidiscip Healthc. 2012; 5:97-113.

11. Reis C, Heisler M, Amowitz LL, et al. Discriminatory attitudes and practices by health workers towards patients with HIV/AIDS in Nigeria. PLoS Med. 2005; 2(8):e246.

12. Kermode M, Holmes W, Langkham B, Thomas MS, Gifford S. HIVrelated knowledge, attitudes and risk perception amongst nurses, doctors and other healthcare workers in rural India. Indian J Med Res. 2005; 122(3):258-64

13. Philip J, Chadee D, Yearwood R. Health care students' reactions towards HIV patients: examining prejudice, emotions, attribution of blame and willingness to interact with HIV/AIDS patients. AIDS Care: Psychological and Socio-medical Aspects of AIDS/HIV. 2014; 26(10):1236-41.

14. Jin H, Earnshaw VA, Wickersham JA, et al. An assessment of health-care students' attitudes toward patients with or at high risk for HIV: implications for education and cultural competency. AIDS Care. 2014; 26(10):1223-8.

15. Platten M, Pham HN, Nguyen HV, Nguyen T, Le GM. Knowledge of HIV and factors associated with attitudes towards HIV among final-year medical students at Hanoi medical university in Vietnam. BMC Public Health. 2014; 14:265.

16. Varas-Díaz N, Neilands TB. Development and validation of a culturally appropriate HIV/AIDS Stigma Scale for Puerto Rican health professionals in training. AIDS Care. 2009; 21(10):1259-70.

17. Kipp AM, Audet CM, Earnshaw VA, Owens J, McGowan CC, Wallston KA. Re-Validation of the Van Rie HIV/AIDS-Related Stigma Scale for use with people living with HIV in the United States. PLoS ONE. 2015; 10(3): e0118836

18. Nyblade L, Jain A, Benkirane M, et al. A brief, standardized tool for measuring HIV-related stigma among health facility staff: results of field testing in China, Dominica, Egypt, Kenya, Puerto Rico and St. Christopher \& Nevis. J Int AIDS Soc. 2013; 16(3 Suppl 2):18718.

19. Trinidad A, Quinto D, Naldoza R. The experiences of external and internal stigma of HIV positive Filipinos. Philippine Population Review. $2011 ; 10(1): 43-63$.

20. AIDS Society of the Philippines [Online]. 2012 [cited 2016 Nov]. Available from http://www.aidsphil.org/.

21. The People Living with HIV Stigma Index [Online]. [cited 2016 Nov]. . Available from http://www.stigmaindex.org/.

22. Nyblade L, Stangl A, Weiss E, Ashburn K. Combating HIV stigma in health care settings: what works? J Int AIDS Soc. 2009; 12:15.

23. Occupational Safety and Health Center, Republic of the Philippines Department of Labor and Employment. Implementing Rules and Regulations on STD/HIV/AIDS [Online]. [cited 2016 Nov]. Available from http://www.oshc.dole.gov.ph/328/. 


\section{Appendix. Results Tables}

A. Infection concerns in health facility $(\mathrm{N}=375)$

\begin{tabular}{|c|c|c|c|}
\hline Level of worry when conducting the following activities ${ }^{a}$ & Worried (\%) & Not worried (\%) & Not applicable (\%) \\
\hline Touched the clothing or bedding of a patient living with HIV $(\mathrm{n}=374)$ & 23.3 & 73.5 & 3.2 \\
\hline Dressed the wounds of a patient living with HIV $(n=372)$ & 80.4 & 14.2 & 5.4 \\
\hline Drew blood from a patient living with HIV $(n=371)$ & 87.1 & 8.1 & 4.9 \\
\hline Took the temperature of a patient living with $\operatorname{HIV}(n=372)$ & 13.7 & 82 & 4.3 \\
\hline Typical use of any of the following measures when providing services to a patient living with HIV & Yes $(\%)$ & No $(\%)$ & Not applicable (\%) \\
\hline Avoid physical contact $(\mathrm{n}=373)$ & 21.2 & 74.8 & 3.8 \\
\hline Wear double gloves $(n=371)$ & 72.8 & 25.3 & 1.9 \\
\hline Wear gloves during all aspects of the patient's care $(n=369)$ & 70.2 & 28.7 & 1.1 \\
\hline $\begin{array}{l}\text { Use any special infection-control measures with patients living with HIV that you do not use with other } \\
\text { patients }(n=368)\end{array}$ & 76.1 & 22.3 & 1.6 \\
\hline
\end{tabular}

$\mathrm{n}=$ number of responses.

aResponse categories: very worried, worried, a little worried, a not worried; results collapse responses.

\section{B. Practices in health facility $(\mathbf{N}=375)$}

\begin{tabular}{|c|c|c|}
\hline Observed stigma & At least once (\%) & Never (\%) \\
\hline \multicolumn{3}{|l|}{ In $<12$ months, how often are the following observed a: } \\
\hline Healthcare workers unwilling to care for a patient living with or thought to be living with HIV (n=329) & 42.9 & 57.1 \\
\hline $\begin{array}{l}\text { Healthcare workers providing poorer quality of care to a patient living with or thought to be living with HIV than to } \\
\text { other patients }(n=321)\end{array}$ & 28.7 & 71.0 \\
\hline Healthcare workers talking badly about people living with or thought to be living with HIV (n=319) & 48.6 & 51.4 \\
\hline Experience with secondary stigma & Worried (\%) & Not worried $(\%)$ \\
\hline \multicolumn{3}{|l|}{ How worried are you about ${ }^{\mathrm{b}}$ : } \\
\hline People talking badly about you because you care for patients living with HIV (n=252) & 16.3 & 83.7 \\
\hline Friends and family avoiding you because you care for patients living with HIV (n=249) & 18.1 & 81.9 \\
\hline \multirow[t]{2}{*}{ Colleagues avoiding you because of your work caring for patients living with HIV (n=244) } & 16.4 & 83.6 \\
\hline & Hesitant $(\%)$ & Not hesitant (\%) \\
\hline $\begin{array}{l}\text { How hesitant are healthcare workers in this facility to work alongside a co-worker living with HIV, regardless of } \\
\text { their duties? }(\mathrm{n}=358)\end{array}$ & 56.7 & 43.3 \\
\hline
\end{tabular}
their duties? ( $\mathrm{n}=358)$

$\mathrm{n}=$ number of responses.

a Response categories included most of the time, several times, once or twice and never.

bResponse categories very worried, worried, a little worried, a not worried; results collapse responses.

C. Health facility policies $(\mathbf{N}=375)$

\begin{tabular}{|c|c|c|c|}
\hline Agreement with the following statements ${ }^{a}$ & Agree (\%) & Disagree $(\%)$ & Don't know (\%) \\
\hline In my facility it is not acceptable to test a patient for HIV without their knowledge. $(n=370)$ & 91.6 & 8.4 & \multirow{4}{*}{21.6} \\
\hline I will get in trouble at work if I discriminate against patients living with HIV (n=370) & 71.1 & 7.0 & \\
\hline There are adequate supplies in my health facility that reduce my risk of becoming infected with HIV ( $\mathrm{n}=373$ ) & 43.2 & 56.8 & \\
\hline $\begin{array}{l}\text { There are standardized procedures/protocols in my health facility that reduce my risk of becoming infected } \\
\text { with HIV. }(n=370)\end{array}$ & 76.5 & 23.5 & \\
\hline & Yes $(\%)$ & No $(\%)$ & Don't know (\%) \\
\hline
\end{tabular}

$\mathrm{n}=$ number of responses.

${ }^{a}$ Response categories: strongly agree, agree, disagree, and strongly disagree; results collapse responses. 
D. Opinions about people living with HIV $(\mathbf{N}=375)$

\begin{tabular}{|c|c|c|}
\hline Level of agreement with the following statements ${ }^{a}$ & Agree (\%) & Disagree $(\%)$ \\
\hline Most people living with HIV do not care if they infect other people. $(\mathrm{n}=369)$ & 27.1 & 72.9 \\
\hline People living with HIV should feel ashamed of themselves. $(\mathrm{n}=372)$ & 10.8 & 89.2 \\
\hline Most people living with HIV have had many sexual partners. (n=369) & 66.4 & 33.3 \\
\hline People get infected with HIV because they engage in irresponsible behaviors. $(\mathrm{n}=369)$ & 69.1 & 30.9 \\
\hline HIV is punishment for bad behavior $(n=372)$ & 6.2 & 93.5 \\
\hline Women living with HIV should be allowed to have babies if they wish. (n=367) & 63.2 & 36.8 \\
\hline If I had a choice, I would prefer not to provide services to people who inject illegal drugs. ( $n=357)$ & 26.3 & 73.7 \\
\hline \multicolumn{3}{|l|}{ If agree, reason: } \\
\hline They put me at higher risk for disease. $(\mathrm{n}=86)$ & 84.9 & 15.1 \\
\hline This group engages in immoral behavior. $(\mathrm{n}=79)$ & 67.1 & 32.9 \\
\hline I have not received training to work with this group $(n=79)$ & 74.7 & 25.3 \\
\hline If I had a choice, I would prefer not to provide services to men who have sex with men. ( $\mathrm{n}=346$ ) & 7.8 & 92.2 \\
\hline \multicolumn{3}{|l|}{ If agree, reason: } \\
\hline They put me at higher risk for disease. $(\mathrm{n}=27)$ & 85.2 & 14.8 \\
\hline This group engages in immoral behavior. $(n=24)$ & 70.8 & 29.2 \\
\hline I have not received training to work with this group $(n=23)$ & 52.2 & 47.8 \\
\hline If I had a choice, I would prefer not to provide services to sex workers. $(\mathrm{n}=349)$ & 13.2 & 86.5 \\
\hline \multicolumn{3}{|l|}{ If agree, reason: } \\
\hline They put me at higher risk for disease. $(\mathrm{n}=42)$ & 83.3 & 14.3 \\
\hline This group engages in immoral behavior. $(\mathrm{n}=37)$ & 43.2 & 56.8 \\
\hline I have not received training to work with this group $(\mathrm{n}=37)$ & 59.5 & 40.5 \\
\hline
\end{tabular}

$\mathrm{n}=$ number of responses.

aResponse categories: strongly agree, agree, disagree, and strongly disagree; results collapse responses.

E. Antenatal care, prevention of mother-to-child transmission, and labor and delivery wards $(\mathbf{N}=\mathbf{3 7 5})$

\begin{tabular}{|c|c|c|}
\hline Level of worry when conducting the following ${ }^{a}$ & Worried (\%) & Not worried (\%) \\
\hline Assisting in labor and delivery if the woman is living with HIV $(n=283)$ & 82.0 & 9.5 \\
\hline Observed stigma & At least once $(\%)$ & Never $(\%)$ \\
\hline \multicolumn{3}{|l|}{ In the past 12 months, how often have you observed other healthcare providers ${ }^{\mathrm{b}}$ : } \\
\hline Performing an HIV test on a pregnant woman without her informed consent? $(n=273)$ & 10.6 & 89.4 \\
\hline Neglecting a woman living with HIV during labor and delivery because of her HIV status? (n=272) & 6.3 & 93.8 \\
\hline $\begin{array}{l}\text { Using additional infection-control procedures (e.g., double gloves) with a pregnant woman living with HIV during } \\
\text { labor and delivery because of her HIV status? }(n=263)\end{array}$ & 72.2 & 27.8 \\
\hline Disclosing the status of a pregnant woman living with HIV to others without her consent? $(\mathrm{n}=269)$ & 29.7 & 70.3 \\
\hline Making HIV treatment for a woman living with HIV conditional on her use of family planning methods? $(\mathrm{n}=262)$ & 33.2 & 66.8 \\
\hline Level of agreement with the following statements ${ }^{c}$ & Agree (\%) & Disagree $(\%)$ \\
\hline If a pregnant woman is HIV positive, her family has a right to know. $(\mathrm{n}=274)$ & 82.1 & 17.9 \\
\hline Pregnant women who refuse HIV testing are irresponsible. $(n=275)$ & 60.7 & 39.3 \\
\hline Women living with HIV should not get pregnant if they already have children. $(n=273)$ & 49.1 & 50.9 \\
\hline It can be appropriate to sterilize a woman living with HIV, even if this is not her choice. $(n=271)$ & 19.9 & 80.1 \\
\hline
\end{tabular}

$\mathrm{n}=$ number of responses.

aResponse categories: very worried, worried, a little worried, a not worried; results collapse responses.

${ }^{b}$ Response categories included most of the time, several times, once or twice and never.

cResponse categories: strongly agree, agree, disagree, and strongly disagree; results collapse responses. 